Article

\title{
Oxidative Leaching of Vanadium from Vanadium-Chromium Reducing Residue with $\mathrm{MnO}_{2}$
}

\author{
Hao Peng*, Liu Yang, Ya Chen, Jing Guo \\ College of Chemistry and Chemical Engineering, Yangtze Normal University, 408102, Chongqing, China; \\ yznuly@126.com (L. Y.); yznucy@126.com (C. Y.); cquguojing@126.com (J. G.) \\ * Correspondence: cqupenghao@126.com; Tel.: +86-15123031643
}

\begin{abstract}
This paper focused on the oxidative leaching process of vanadium from vanadium-chromium reducing residue in alkaline medium with $\mathrm{MnO}_{2}$. The effect of experimental parameters including reaction time, reaction temperature, dosage of $\mathrm{MnO}_{2}$, dosage of $\mathrm{NaOH}$, and liquid-to-solid ratio on the leaching efficiency of vanadium had been studied. The results indicated that $\mathrm{MnO}_{2}$ was an efficient oxidant for leaching out of vanadium. The leaching efficiency of vanadium was up to $97.25 \%$ under optimal reaction conditions: reaction temperature of $90{ }^{\circ} \mathrm{C}$, reaction time of $60 \mathrm{~min}$, dosage of $\mathrm{MnO}_{2}$ at $50 \mathrm{wt} . \%$, concentration of $\mathrm{NaOH}$ at $30 \mathrm{wt} . \%$ and liquid-to-solid at $5: 1 \mathrm{~mL} / \mathrm{g}$.
\end{abstract}

Keywords: leaching; vanadium; $\mathrm{MnO}_{2}$

\section{Introduction}

The vanadium compounds as important national strategy resources were widely used in petrochemical industry, catalyst, iron steel, due to its excellent physicochemical properties and also it was called as "vitamins of modern industry" [1-6]. As it had an electronic configuration of [Ar] $3 \mathrm{~d}^{3} 4 \mathrm{~s}^{2}$, the vanadium valence could be $\mathrm{V}(\mathrm{II}), \mathrm{V}(\mathrm{III}), \mathrm{V}(\mathrm{IV})$ and $\mathrm{V}(\mathrm{V})$ the most common oxidation states [7]. In China, the main sources of vanadium were vanadium-titan magnetite ore [8] and stone coal [9] and the vanadium was almost existed in low valence. In the vanadium producing process, a large amount wastewater containing $\mathrm{V}(\mathrm{V})$ and $\mathrm{Cr}(\mathrm{VI})$ was produced. The wastewater was reduced with $\mathrm{Na}_{2} \mathrm{SO}_{3}$ or iron scurf to form the precipitate containing $\mathrm{Cr}$ (III), $\mathrm{V}$ (IV) and $\mathrm{V}$ (III), which was usually called vanadium-chromium reducing residue. In which, vanadium mainly occurs as $\mathrm{V}$ (IV) and V (III). In China, every year more than 500 thousand tons of the vanadium-chromium reducing residue was produced. The handling of these residues had become a thorny problem in many plants in China

Many hydrometallurgy technologies had been investigated to recover vanadium from the vanadium-chromium reducing residue, directing leaching with $\mathrm{NaOH}$ [10], alkaline leaching with electric field $[11,12]$. The sub-molten salt (SMS) technology had been successfully applied to leach out vanadium in concentrated alkaline solution[13-16]. The leaching efficiency of vanadium could reach up to $95 \%$ and no hazardous gas or toxic tailings were discharged during the process. But the process needed high alkaline consumption, high energy cost and the equipment corrosion was a big challenge due to the high causticity of the reaction medium (usually above $70 \mathrm{wt} \%$ ). The vanadium-chromium reducing slag had not been treated effectively, resulting in a waste of vanadium and chromium resources as well as environmental pollution.

In this paper, $\mathrm{MnO}_{2}$ was used to oxidize the low valent vanadium during the alkaline leaching process. The effect of reaction time, reaction temperature, dosage of $\mathrm{MnO}_{2}$ dosage of $\mathrm{NaOH}$ and liquid-to-solid ratio on the leaching efficiency of vanadium were investigated.

\section{Materials and Methods}

\subsection{Materials}


The vanadium-chromium reducing residue was precipitated from a waste water contained vanadium and chromium in low valence in an iron and steel mill from Pan gang Group Co., Ltd., Panzhihua, Sichuan Province, China. Before the experiment, the residue dried and grounded to suitable particles. The chemical composition of the residue was listed in Table 1 and the phase composition was detailed in Figure 1. All the reagents used in the experiments were analytical grade.

\subsection{Experimental procedure}

All experiments were performed in a glass beaker with a thermostatic mixing water bath pot $[11,17,18]$.

A predetermined amount of $\mathrm{NaOH}$ and deionized water was added to the beaker to produce homogeneous slurry under constant stirring. The slurry was heated to a predetermined temperature. Next, the residue was added to the reactor, and then the amount of $\mathrm{MnO}_{2}$ was added. After the required contact time, the filtrate was separated from the residue by vacuum filtration. The concentration of vanadium in the filtrate was determined by inductive couple plasma-optical mission spectrometry (ICP-3000).

The leaching efficiency of vanadium $\left(\eta_{\mathrm{V}}\right)$ was calculated in Equation (1), as followed:

$$
\eta=\frac{\mathrm{V} \cdot \mathrm{C}}{\mathrm{m} \omega} \times 100 \%
$$

Where, $C$ is the concentration of vanadium in the filtrate, $\mathrm{g} / \mathrm{L} ; V$ is the volume of the filtrate, $\mathrm{mL} ; \omega$ is the mass fraction of vanadium in the vanadium-chromium reducing residue; $m$ is mass of the vanadium-chromium reducing residue used in the leaching experiments, $\mathrm{g}$.

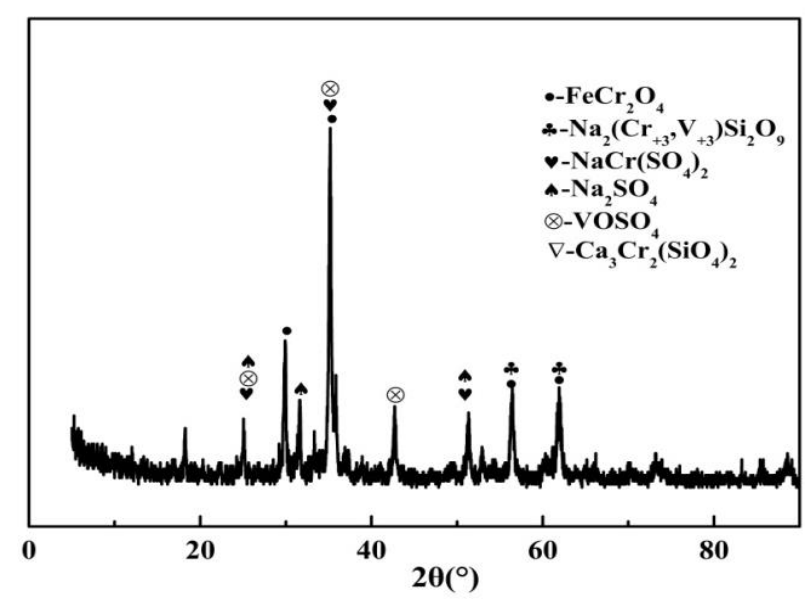

Figure 1 The XRD pattern of the original residue

Table 1 Composition of the original vanadium and chromium residue $(\%, w t)$

\begin{tabular}{lllllll}
\hline Component & $\mathrm{O}$ & $\mathrm{Cr}$ & $\mathrm{Si}$ & $\mathrm{Na}$ & $\mathrm{S}$ & $\mathrm{V}$ \\
\hline Amount (wt.\%) & 41.44 & 18.80 & 11.30 & 10.93 & 10.64 & 3.11 \\
Component & $\mathrm{Ca}$ & $\mathrm{Cl}$ & $\mathrm{Fe}$ & $\mathrm{K}$ & & \\
Amount (wt.\%) & 1.94 & 1.06 & 0.37 & 0.17 & & \\
\hline
\end{tabular}

\section{Results and Discussion}

\subsection{Reaction mechanism}


The vanadium existed as low valent in vanadium-chromium reducing residue according to the results showed in Figure 1, and it was hard to leach out in alkaline medium [10]. It was known that $\mathrm{E}^{0}{ }_{\mathrm{MnO} / \mathrm{Mn} 2+}=1.21$ $\mathrm{V}$ and $\mathrm{E}^{0}\left(\mathrm{VO}_{2}{ }^{+} / \mathrm{VO}^{2+}\right)=1.00 \mathrm{~V}$, and therefore $\mathrm{MnO}_{2}$ might be used as the oxidizing agent to oxidize $\mathrm{V}(\mathrm{IV})$ in the leaching process $[19,20]$. Thus, the main reaction during the oxidative leaching process was between the low valent vanadium and $\mathrm{MnO}_{2}$ like Equation (2) and (3). The $\Delta \mathrm{G}_{\mathrm{T}}^{\theta}$ of Equation (2) and (3) at different temperatures could be calculated with $\Delta_{\mathrm{f}} \mathrm{H}_{298}^{\theta}, \mathrm{S}_{298}^{\theta}$ and $\mathrm{C}_{\mathrm{p}}$ at $298 \mathrm{~K}[21,22]$. The results showed in Figure 2 showed that the $\triangle \mathrm{G}$ was negative which indicated that the reaction of Equations (2) and (3) were easy to happen and the oxidative leaching of vanadium with $\mathrm{MnO}_{2}$ was feasible.

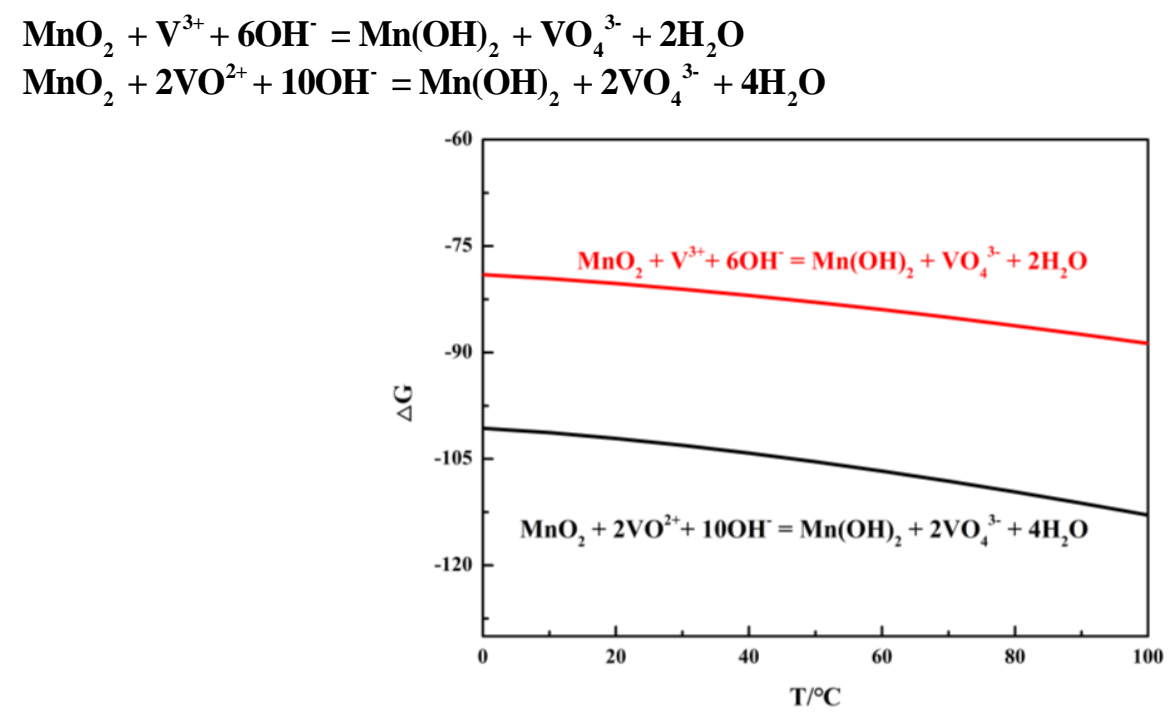

Figure 2 Relationship between $\triangle \mathrm{G}$ and temperature of oxidation of vanadium with $\mathrm{MnO}_{2}$

\subsection{Effect of dosage of $\mathrm{MnO}_{2}$}

Based on the above, the oxidation reaction of low valence vanadium and $\mathrm{MnO}_{2}$ was easy to happen in thermodynamics. It was known that $\mathrm{E}^{0}{ }_{\mathrm{MnO} 2 / \mathrm{Mn} 2+}=1.21 \mathrm{~V}$ and $\mathrm{E}^{0}\left(\mathrm{VO}_{2}{ }^{+} / \mathrm{VO}^{2+}\right)=1.00 \mathrm{~V}$, and therefore $\mathrm{MnO}_{2}$ could be used for the oxidation of V(IV) during the leaching process. The effect of $\mathrm{MnO}_{2}$ dosage on the leaching efficiency of vanadium was investigated as other reaction conditions kept as constant: reaction time of $60 \mathrm{~min}$, reaction temperature of $90^{\circ} \mathrm{C}$, liquid-to-solid ratio of $5: 1 \mathrm{~mL} / \mathrm{g}$, and dosage of $\mathrm{NaOH}$ at 30 wt.\%. The results were shown in Figure 3.

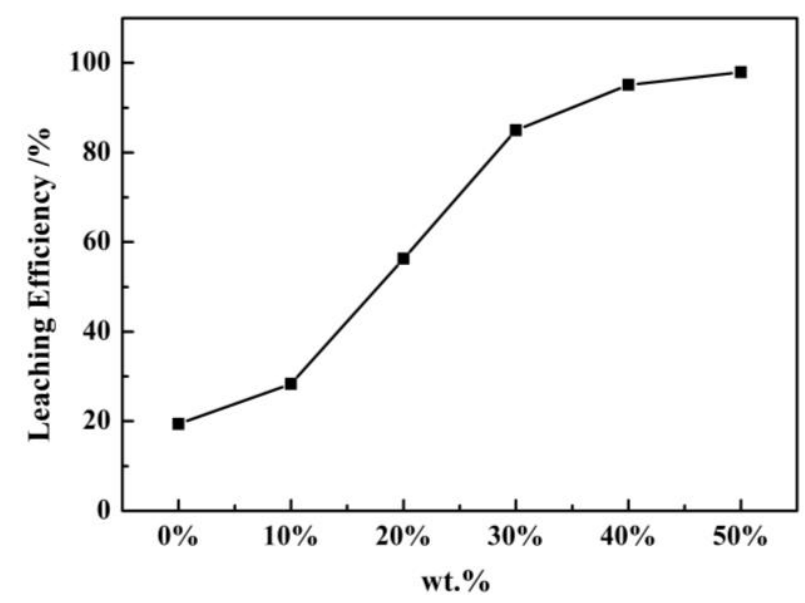

Figure 3 Effect of dosage of $\mathrm{MnO}_{2}$ on the leaching efficiency of vanadium 
The leaching efficiency of vanadium was increased linearly with the increase of dosage of $\mathrm{MnO}_{2}$. The leaching efficiency of vanadium was increased from $19.38 \%$ without $\mathrm{MnO}_{2}$ to $97.25 \%$ at dosage of $\mathrm{MnO}_{2}$ at 50 wt. \%. The vanadium in low valences like V(IV) and V(III) was oxidized to V(V) by $\mathrm{MnO}_{2}$, and then dissolved in alkaline medium and achieved high leaching efficiency. The results confirmed that $\mathrm{MnO}_{2}$ could oxidize low valence vanadium ion of $\mathrm{V}(\mathrm{IV})$ and $\mathrm{V}(\mathrm{III})$ into $\mathrm{V}(\mathrm{V})$.

\subsection{Effect of dosage of $\mathrm{NaOH}$}

Results shown in Figure 4 summarized the effect of dosage of $\mathrm{NaOH}$ on the leaching efficiency of vanadium as the reaction conditions kept as: reaction time at $60 \mathrm{~min}$, reaction temperature of $90{ }^{\circ} \mathrm{C}$, liquid-to-solid ratio of 5:1 mL/g and dosage of $\mathrm{MnO}_{2}$ at $50 \mathrm{wt} . \%$. The concentration of $\mathrm{NaOH}$ was set as 0 wt. $\%, 10$ wt.\%, 15 wt. $\%, 20$ wt. $\%, 25$ wt.\% and 30 wt. $\%$.

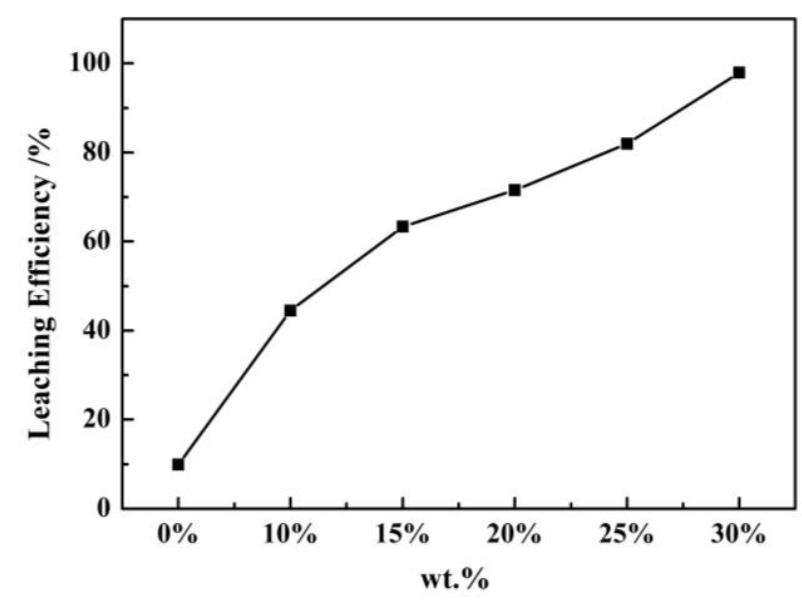

Figure 4 Effect of dosage of $\mathrm{NaOH}$ on the leaching efficiency of vanadium

The leaching efficiency of vanadium was increased with the increasing of dosage of $\mathrm{NaOH}$. About 9.94\% vanadium leached out in neutral medium with oxidation of $\mathrm{MnO}_{2}$. And the leaching efficiency increased up to $97.25 \%$ at $\mathrm{NaOH}$ of $30 \mathrm{wt} . \%$. The vanadium in low valence was hard to leach out in alkaline medium, while the high valent vanadium was easy to dissolve in alkaline medium and achieve high leaching efficiency. The high concerned $\mathrm{NaOH}$ solution was beneficial for high valent vanadium leaching out. As the leaching efficiency had up to $97.25 \%$, thus the dosage of $\mathrm{NaOH}$ at 30 wt.\% was chosen for optimal condition for further experiments.

\subsection{Effect of reaction temperature}

Reaction temperature played an important role in the diffusion process. The higher temperature increased the activity of atoms and molecules, and therefore the reaction rate [23]. Figure 5 summarized the effect of reaction temperature on the leaching process under standard conditions: reaction time of 60 min, liquid-to-solid ratio of $5: 1 \mathrm{~mL} / \mathrm{g}$, dosage of $\mathrm{MnO}_{2}$ at $50 \mathrm{wt} . \%$ and concentration of $\mathrm{H}_{2} \mathrm{SO}_{4}$ at $30 \mathrm{wt}$.\%. The leaching efficiency of vanadium was improved by increasing the reaction temperature. $97.25 \%$ of vanadium could leach out at a reaction temperature of $90{ }^{\circ} \mathrm{C}$ and therefore $90{ }^{\circ} \mathrm{C}$ was chosen for optimal reaction temperature in further experiments. 


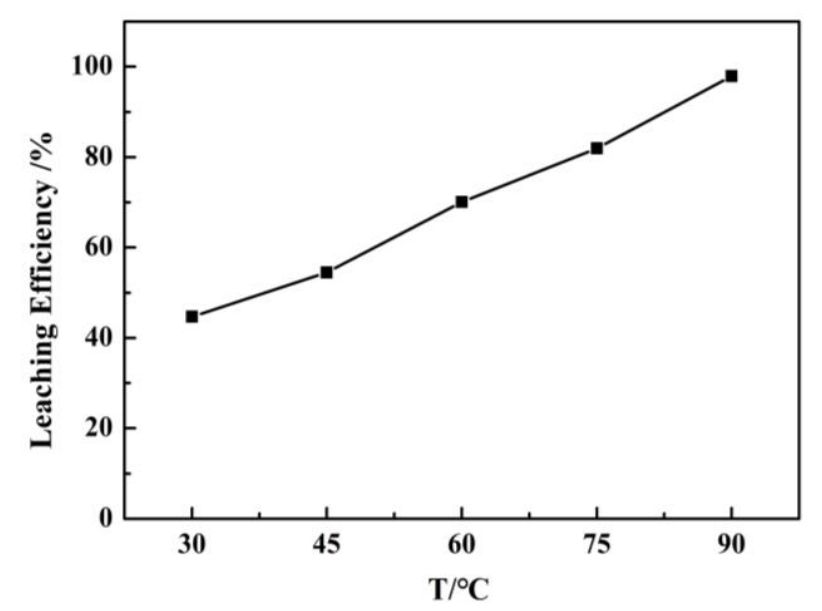

Figure 5 Effect of dosage of reaction temperature on the leaching efficiency of vanadium

\subsection{Effect of reaction time}

Figure 6 showed the leaching efficiency of vanadium by varying the reaction time from $10 \mathrm{~min}$ to 60 min under selected conditions: reaction temperature of $90^{\circ} \mathrm{C}$, liquid-to-solid ratio of $5: 1 \mathrm{~mL} / \mathrm{g}$, dosage of $\mathrm{MnO}_{2}$ at $50 \mathrm{wt} . \%$ and concentration of $\mathrm{NaOH}$ at $30 \mathrm{wt} . \%$. Increasing of reaction time could promote the reaction between $\mathrm{MnO}_{2}$ and low valent vanadium in alkaline medium and achieve high leaching efficiency. The leaching efficiency of vanadium was increased from $49.69 \%$ at $10 \mathrm{~min}$ to $97.25 \%$ at 60 min. which indicated that 60 min was enough to leach out vanadium.

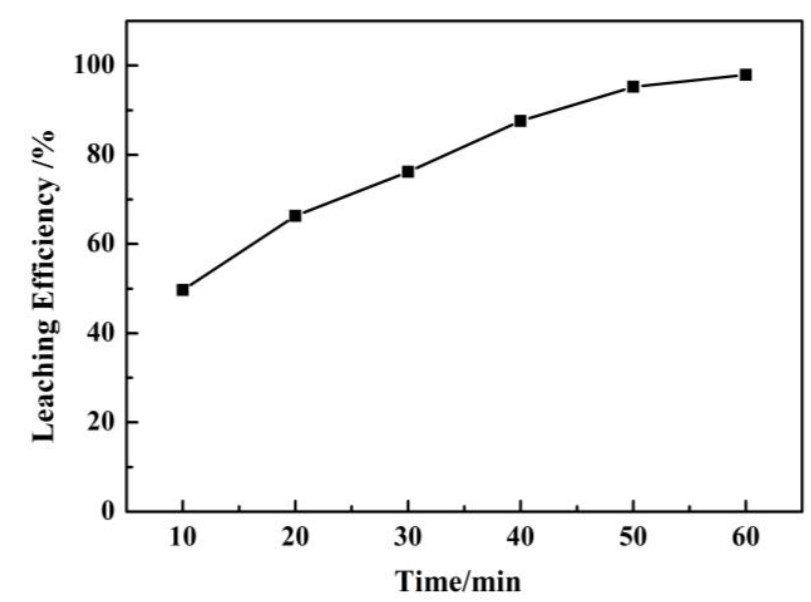

Figure 6 Effect of dosage of reaction time on the leaching efficiency of vanadium

\subsection{Effect of liquid-to-solid ratio}

The liquid-to-solid ratio showed a significant effect on the volume of filtrate and concentration of purpose product in the leaching process [23]. A series of experiments were conducted to evaluate an optimal liquid-to-solid ratio to achieve high leaching efficiency of vanadium. The liquid-to-solid ratio was set as $3: 1 \mathrm{~mL} / \mathrm{g}, 4: 1 \mathrm{~mL} / \mathrm{g}, 5: 1 \mathrm{~mL} / \mathrm{g}, 6: 1 \mathrm{~mL} / \mathrm{g}$ and $7: 1 \mathrm{~mL} / \mathrm{g}$, and other reaction conditions were kept as constant: reaction temperature of $90{ }^{\circ} \mathrm{C}$, reaction time of $60 \mathrm{~min}$, dosage of $\mathrm{MnO}_{2}$ at $50 \mathrm{wt} . \%$ and concentration of $\mathrm{NaOH}$ at 30 wt. \%. The results were shown in Figure 7. 


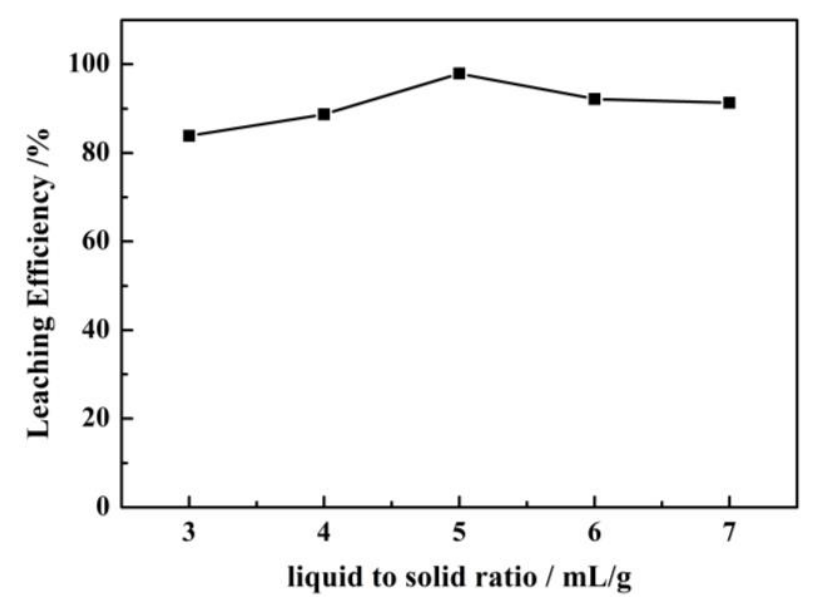

Figure 7 Effect of dosage of liquid-to-solid ratio on the leaching efficiency of vanadium

The leaching process was inefficient for low liquid-to-solid ratio as the viscosity of reaction medium was large, just $83.85 \%$ of vanadium were leached out in liquid-to-solid at $3: 1 \mathrm{~mL} / \mathrm{g}$. The leaching process favored higher liquid-to-solid ratio, where $97.25 \%$ of the vanadium was obtained at a liquid-to-solid of 5:1 $\mathrm{mL} / \mathrm{g}$. While further increase of the liquid-to-solid ratio had negative effect on the leaching process. Therefore, a liquid-to-solid of $5: 1 \mathrm{~mL} / \mathrm{g}$ was recommended for future use.

Based upon the above experimental results, the optimal reaction conditions for vanadium leaching out was: reaction temperature of $90^{\circ} \mathrm{C}$, reaction time of $60 \mathrm{~min}$, dosage of $\mathrm{MnO}_{2}$ at $50 \mathrm{wt}$. $\%$, concentration of $\mathrm{NaOH}$ at 30 wt.\% and liquid-to-solid at $5: 1 \mathrm{~mL} / \mathrm{g}$. The leaching efficiency of vanadium was up to $97.25 \%$ under optimal reaction conditions.

\section{Conclusions}

This paper focused on the oxidative leaching process of vanadium with $\mathrm{MnO}_{2}$ from vanadium-chromium reducing residue. Vanadium in low valent could be oxidized to high valent by $\mathrm{MnO}_{2}$ in the alkaline leaching process, which contributed to high leaching efficiency of vanadium and it was up to $97.25 \%$ under optimal reaction conditions: reaction temperature of $90{ }^{\circ} \mathrm{C}$, reaction time of $60 \mathrm{~min}$, dosage of $\mathrm{MnO}_{2}$ at $50 \mathrm{wt} . \%$, concentration of $\mathrm{NaOH}$ at $30 \mathrm{wt} . \%$ and liquid-to-solid at 5:1 mL/g.

Author Contributions: Conceptualization, Hao Peng; Methodology, Liu Yang; Validation, Hao Peng; Formal Analysis, Jing Guo; Investigation, Ya Chen; Resources, Hao Peng; Data Curation, Jing Guo; Writing-Original Draft Preparation, Hao Peng; Supervision, Hao Peng; Project Administration, Hao Peng; Funding Acquisition, Hao Peng.

Funding: This work was supported by the Science and Technology Project of Chongqing, China (cstc2018jcyjAX0018).

Conflicts of Interest: The authors declare no conflict of interest.

\section{References}

[1] M.H. Anjass, K. Kastner, F. Nagele, M. Ringenberg, J.F. Boas, J. Zhang, A.M. Bond, T. Jacob, C. Streb, Stabilization of Low-Valent Iron(I) in a High-Valent Vanadium(V) Oxide Cluster, Angew Chem Int Ed Engl, 56 (2017) 14749-14752.

[2] Z. Wei, D. Liu, C. Hsu, F. Liu, All-vanadium redox photoelectrochemical cell: An approach to store solar energy, Electrochemistry Communications, 45 (2014) 79-82. 
[3] M.B. Smirnov, V.Y. Kazimirov, R. Baddour-Hadjean, K.S. Smirnov, J.-P. Pereira-Ramos, Atomistic mechanism of phase transition in vanadium pentoxide, Journal of Physics and Chemistry of Solids, 75 (2014) 115-122.

[4] V.Y. Zadorozhnyy, S.N. Klyamkin, M.Y. Zadorozhnyy, O.V. Bermesheva, S.D. Kaloshkin, Mechanical alloying of nanocrystalline intermetallic compound TiFe doped by aluminum and chromium, Journal of Alloys and Compounds, 586 (2014) S56-S60.

[5] V. Efremenko, K. Shimizu, Y. Chabak, Effect of Destabilizing Heat Treatment on Solid-State Phase Transformation in High-Chromium Cast Irons, Metall and Mat Trans A, 44 (2013) 5434-5446.

[6] M. Lübke, N. Ding, M.J. Powell, D.J.L. Brett, P.R. Shearing, Z. Liu, J.A. Darr, VO2 nano-sheet negative electrodes for lithium-ion batteries, Electrochemistry Communications, 64 (2016) 56-60.

[7] E. Del Carpio, L. Hernández, C. Ciangherotti, V. Villalobos Coa, L. Jiménez, V. Lubes, G. Lubes, Vanadium: History, chemistry, interactions with $\alpha$-amino acids and potential therapeutic applications, Coordination Chemistry Reviews, 372 (2018) 117-140.

[8] E. Janssens, S.M. Lang, M. Brummer, A. Niedziela, G. Santambrogio, K.R. Asmis, J. Sauer, Kinetic study of the reaction of vanadium and vanadium-titanium oxide cluster anions with SO2, Physical chemistry chemical physics : PCCP, 14 (2012) 14344-14353.

[9] D. He, Q. Feng, G. Zhang, L. Ou, Y. Lu, An environmentally-friendly technology of vanadium extraction from stone coal, Minerals Engineering, 20 (2007) 1184-1186.

[10] Y. Kang, Z. Xiaoyun, T. Xueda, Y. Yonglong, C. Yanbo, Leaching of vanadium from chromium residue, Hydrometallurgy, 103 (2010) 7-11.

[11] H. Peng, Z. Liu, C. Tao, Selective leaching of vanadium from chromium residue intensified by electric field, Journal of Environmental Chemical Engineering, 3 (2015) 1252-1257.

[12] Z. Liu, A. Nueraihemaiti, M. Chen, J. Du, X. Fan, C. Tao, Hydrometallurgical leaching process intensified by an electric field for converter vanadium slag, Hydrometallurgy, 155 (2015) 56-60.

[13] L. Huibin, D. Hao, W. Dawei, W. Shaona, Z. Shili, Z. Yi, Kinetics analysis of decomposition of vanadium slag by KOH sub-molten salt method, Transactions of Nonferrous Metals Society of China, 23 (2013) 1489-1500.

[14] L. Biao, D. Hao, W. ShaoNa, Z. Yi, Z. ShiLi, L. LanJie, C. DongHui, A novel method to extract vanadium and chromium from vanadium slag using molten NaOH-NaNO3binary system, AIChE Journal, 59 (2013) 541-552.

[15] X. Hongbin, Z. Shili, Z. Yi, L. Zi, W. Z, Oxidative leaching of a Vietnamese chromite ore in highly concentrated potassium hydroxide aqueous solution at $300^{\circ} \mathrm{C}$ and atmospheric pressure, Minerals Engineering, 18 (2005) 527-535.

[16] Z. Hai, X. Hongbin, Z. Xiaofei, Z. Yang, Z. Yi, Pressure oxidative leaching of Indian chromite ore in concentrated $\mathrm{NaOH}$ solution, Hydrometallurgy, 142 (2014) 47-55.

[17] H. Peng, Z. Liu, C. Tao, Leaching Kinetics of Vanadium with Electro-oxidation and H2O2in Alkaline Medium, Energy \& Fuels, 30 (2016) 7802-7807.

[18] H. Peng, Z. Liu, C. Tao, A green method to leach vanadium and chromium from residue using $\mathrm{NaOH}-\mathrm{H} 2 \mathrm{O} 2$, Scientific Reports, 8 (2018) 426.

[19] M. Wang, B. Chen, S. Huang, X. Wang, B. Liu, Q. Ge, S. Xie, A novel technology for vanadium and chromium recovery from V-Cr-bearing reducing slag, Hydrometallurgy, 171 (2017) 116-122.

[20] B. Chen, S. Huang, B. Liu, Q. Ge, M. Wang, X. Wang, Separation and recovery of vanadium and chromium from acidic leach solution of V-Cr-bearing reducing slag, Journal of Environmental Chemical Engineering, 5 (2017) 4702-4706.

[21] H. Peng, J. Guo, Z. Liu, C. Tao, Direct advanced oxidation process for chromium(III) with sulfate free radicals, SN Applied Sciences, 1 (2018).

[22] H. Peng, J. Guo, G. Li, Q. Cheng, Y. Zhou, Z. Liu, C. Tao, Highly efficient oxidation of chromium (III) with hydrogen peroxide in alkaline medium, Water science and technology : a journal of the International Association on Water Pollution Research, 79 (2019) 366-374.

[23] H. Peng, J. Guo, X. Zheng, Z. Liu, C. Tao, Leaching kinetics of vanadium from calcification roasting converter vanadium slag in acidic medium, Journal of Environmental Chemical Engineering, 6 (2018) 5119-5124. 